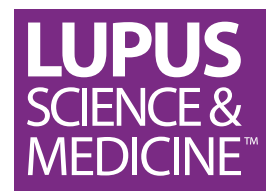

\title{
Hydroxychloroquine treatment in European patients with lupus erythematosus: dosing, retinopathy screening and adherence
}

\author{
Zgjim Osmani (D) , ,2 Thijs J Schrama (D) , ${ }^{1}$ Wendy Zacouris-Verweij, ${ }^{1,2}$ \\ Jeanette Andersen, ${ }^{2}$ Susan Frankel, ${ }^{2}$ Irene E M Bultink (D) , ${ }^{4}$ Alain Cornet, ${ }^{2}$ \\ Ronald F van Vollenhoven (1) ${ }^{5}$
}

To cite: Osmani Z, Schrama TJ, Zacouris-Verweij W, et al. Hydroxychloroquine treatment in European patients with lupus erythematosus: dosing, retinopathy screening and adherence. Lupus Science \& Medicine 2021;8:e000478. doi:10.1136/ lupus-2021-000478

- Additional material is published online only. To view please visit the journal online (http://dx.doi.org/10.1136/ lupus-2021-000478).

Received 14 January 2021 Revised 18 February 2021 Accepted 18 March 2021

\section{Check for updates}

(C) Author(s) (or their employer(s)) 2021. Re-use permitted under CC BY-NC. No commercial re-use. See rights and permissions. Published by BMJ.

${ }^{1}$ LUPUS/APS Committee, Dutch Patient Association NVLE, Utrecht, The Netherlands ${ }^{2}$ Lupus Europe, Romford, UK

${ }^{3}$ Faculty of Medicine and Health Sciences, Erasmus Medical Center, Rotterdam, Zuid-Holland, The Netherlands

${ }^{4}$ Medical Advisory Board, Dutch Patient Association NVLE,

Utrecht, The Netherlands

${ }^{5}$ Medical Advisory Board, Lupus Europe, Romford, UK

Correspondence to

Drs. Zgjim 0smani; info@nvle. org

\section{ABSTRACT}

Background Use of hydroxychloroquine (HCQ) is common in patients with lupus erythematosus. Long-term use (ie, $\geq 5$ years) and high-dose HCQ (ie, $>5 \mathrm{mg} / \mathrm{kg} /$ day) are both risk factors for developing $\mathrm{HCQ}$ retinopathy. Advances in our understanding of $\mathrm{HCQ}$ retinopathy have led to changes in the recommendations for HCQ dosing and retinopathy screening. The latest EULAR guidelines for the management of SLE recommend a maximum HCQ dose of $5 \mathrm{mg} / \mathrm{kg} /$ day and ophthalmological screening at baseline and annually after 5 years of HCQ treatment.

Objectives This study aimed to assess whether the EULAR guidelines are affecting HCQ prescription patterns and screening frequencies in Europe. Furthermore, we inventoried adherence to $\mathrm{HCQ}$.

Results The online questionnaire was completed by 2936 patients with systemic, cutaneous or juvenile lupus from 33 countries. The majority were female $(86.5 \%)$ and diagnosed with SLE (81.2\%). Among those taking HCQ, the median $\mathrm{HCQ}$ dose reported was $4.26 \mathrm{mg} / \mathrm{kg} /$ day. More than one-third of respondents $(36.8 \%)$ exceeded the recommended maximal $\mathrm{HCQ}$ dose of $5 \mathrm{mg} / \mathrm{kg} /$ day. Baseline ophthalmological screening had been done in 857 out of 1017 respondents diagnosed in the past 10 years (84.3\%). Of patients using $\mathrm{HCQ} \geq 5$ years, $69.2 \%$ reported yearly retinopathy screening. Lastly, $17.3 \%$ of patients reported that they skipped HCQ once a week or more often.

Conclusion The results of our study demonstrate that higher than recommended dosages of $\mathrm{HCQ}$ are prescribed to more than one-third of patients with lupus in Europe. Recent recommendations regarding screening for retinopathy are incompletely implemented.

\section{INTRODUCTION}

Hydroxychloroquine (HCQ) is used for the treatment of systemic autoimmune disorders, including lupus erythematosus. Long-term use of HCQ is common in patients with lupus and is generally well tolerated. ${ }^{1}$

It is associated with a wide range of benefits, such as improved survival, reductions of

\section{Key messages}

What is already known about this subject?

- Long-term use (ie, $\geq 5$ years) and high-dose hydroxychloroquine (HCQ; ie, $>5 \mathrm{mg} / \mathrm{kg} /$ day) are both risk factors for developing HCQ retinopathy.

What does this study add?

- More than one-third of patients with lupus in Europe is prescribed HCQ in a dosage above the EULAR recommended maximum of $5 \mathrm{mg} / \mathrm{kg} /$ day.

- Thirty per cent of patients with lupus in Europe using $\mathrm{HCQ}$ for $\geq 5$ years report not to receive retinopathy screening once yearly according to EULAR guidelines.

- Non-adherence to HCQ is frequent, especially in younger patients and in patients diagnosed with lupus at younger age.

How might this impact on clinical practice or future developments?

- Physicians prescribing HCQ should encourage drug adherence and pay more attention to the recent recommendations regarding dosing and ophthalmologic screening.

flares and a lower risk of serious comorbidities. ${ }^{2}$ Although HCQ is generally safe, longterm use (ie, $\geq 5$ years) and high-dose HCQ (ie, $>5 \mathrm{mg} / \mathrm{kg} /$ day) are both risk factors for the development of HCQ retinopathy. ${ }^{3}$ Retinopathy is a serious complication of HCQ use, and recognition at an early stage is essential for preventing irreversible loss of central vision.

New highly sensitive screening methods have enabled early detection of HCQ retinopathy and have consequently resulted in a much higher prevalence than previously recognised. ${ }^{1}$ Advances in our understanding of HCQ retinopathy have led to changes in the recommendations for HCQ dosing and retinopathy screening. ${ }^{1}{ }^{3}$ As a result, the 
latest EULAR guidelines ${ }^{5}$ for the management of SLE recommend a maximum HCQ dose of $5 \mathrm{mg} / \mathrm{kg} /$ day actual body weight and an ophthalmological screening at baseline and annually after 5 years of HCQ treatment. Studies have suggested that prescription patterns in the USA and UK have already been affected by recent guidelines regarding HCQ dosing. ${ }^{1}$ However, in a recent survey study in the Netherlands, ${ }^{6}$ more than one-third of patients with lupus (37\%) reported taking a daily HCQ dose higher than the recommended maximum dose of 5 $\mathrm{mg} / \mathrm{kg}$. Besides proper dosing, non-adherence to HCQ can have important consequences as well; it has been shown to affect drug concentrations in blood of patients with SLE resulting in a higher risk of flares. ${ }^{7}$

As an European association of patients with lupus, we consider (1) dosing, (2) adherence and (3) retinopathy screening three important pillars of HCQ treatment. The primary goal of this study was to assess whether recent guidelines regarding HCQ dosing and retinopathy screening are affecting prescription patterns and screening frequencies in Europe. Second, we aimed to determine patients' adherence to HCQ and to explore factors associated with poor adherence.

\section{METHODS}

Patients with lupus in Europe were invited through social media platforms to complete the online European Survey for Lupus Patients 2019 (ESLP-2019), initiated and developed by LUPUS EUROPE in collaboration with the Dutch Patient Association NVLE. The ESLP-2019 was translated from English into 13 languages (Danish, Dutch, Finnish, French, German, Greek, Hebrew, Italian, Polish, Portuguese, Slovak, Spanish and Swedish). The patient-built questionnaire was reviewed and endorsed by the European Reference Network on Rare and Complex Connective Tissue Diseases (ERN ReCONNET). The questionnaire consisted of 18 questions (online supplemental file A) and was promoted on social media from 26 June to 11 July 2019. Participants gave informed consent before taking part in the ESLP-2019; participation was anonymous and voluntary. Ethical approval was not requested as this was a patient originated and managed survey. Respondents were asked, among other things, to report their diagnosis, body weight $(\mathrm{kg})$, daily HCQ dose, adherence to HCQ and to indicate whether they had received a baseline eye screening and/or regularly undergo eye examinations. They also had the opportunity to report through free text up to 13 different medications they were taking. The patients' self-reported diagnoses were not verified by reviewing medical records. Data of those who reported drug-induced lupus or 'lupus-like' disease as a diagnosis were excluded from the analysis. Survey duplicates were detected and removed based on location and user data (ie, using the same operating system, browser, device). Statistical analyses were performed in $\mathrm{R}$ (V.3.6.3). Differences between groups were tested with the Wilcoxon rank-sum test $\left(\mathrm{W}_{\text {cox }}\right)$ or the Pearson's $\chi^{2}$ test without continuity correction. $\mathrm{P}$ values $\leq 0.05$ were considered statistically significant.

\section{RESULTS}

\section{Study population}

A total of 3543 patients responded to the online survey invitation. Incomplete surveys, duplicates and data from 'lupus-like' or drug-induced patients with lupus were excluded. Ultimately, 2936 patients with lupus (82.9\%) from 33 European countries who completed the online ESLP-2019 survey (online supplemental file B) were considered the study population. Study population characteristics are shown in table 1 .

Most respondents were women (86.5\%), and the majority had been diagnosed with SLE (81.2\%). The median age at diagnosis of the total population was 31 years (IQR: 23-40). Joint (72.0\%) and skin involvement $(50.7 \%)$ were most frequently reported by patients with SLE. Of note, kidney involvement was reported significantly more often by patients with childhood-onset SLE (cSLE) than by patients with adult-onset SLE (52.7\% vs $27.6 \%$, respectively; $\chi^{2} \mathrm{p}<0.001$ ), in line with previous literature. $^{8}$

\section{HCQ prescription patterns}

A total of 1988 patients $(67.7 \%)$ reported current use of HCQ, with a median duration of 6 years (IQR: 3-14). The daily HCQ dose was available from 1674 patients (84.2\%) who reported both their body weight and HCQ dose. The median HCQ dose reported was $4.26 \mathrm{mg} / \mathrm{kg} /$ day (IQR: 3.17-5.71). The recommended maximum HCQ dose of 5 $\mathrm{mg} / \mathrm{kg} /$ day actual body weight was exceeded by 616 out of 1674 patients (36.8\%). In addition, 673 out of 1679 patients $(40.1 \%)$ were prescribed HCQ at a dose $>6.5 \mathrm{mg}$ / $\mathrm{kg}$ /day ideal body weight, which exceeds the previously recommended maximum HCQ dose $^{9-11}$ (online supplemental file C). Regarding HCQ prescription patterns, sufficient data was obtained from 13 out of 33 countries (online supplemental file B), which enabled country comparisons (figure 1, table 2). Data obtained from the remaining 20 countries was insufficient for country comparison due to a low response. The highest median HCQ doses $(\mathrm{mg} / \mathrm{kg} /$ day) were reported by patients from Portugal (5.84), France (5.43), Israel (5.19) and Belgium (5.13). The lowest median HCQ doses were reported by patients from Spain (3.39), Poland (3.68), Great Britain (3.70) and Germany (3.70).

An open-ended question asked participants to list any other medication they used besides HCQ. This question was left unanswered by 167 out of 2936 patients (5.7\%). Fifty-six patients $(1.9 \%)$ reported using chloroquine $(n=47)$ or quinacrine $(n=9)$, and 725 patients $(24.7 \%)$ reported not using any antimalarial drug. Out of these 725 patients, $276(38.1 \%)$ reported using systemic corticosteroids, 250 (34.5\%) immunosuppressants and 118 $(16.3 \%)$ reported not taking any drugs or supplements (table 1). Of note, 493 out of the 725 patients $(68 \%)$ who 


\begin{tabular}{|c|c|}
\hline $\mathbf{N}$ & 2936 \\
\hline Female & $2540(86.5 \%)$ \\
\hline Age (years) & $44(35-53)$ \\
\hline Body weight (kg) & 69 (59-82) \\
\hline \multicolumn{2}{|l|}{ Diagnosis } \\
\hline CLE & $278(9.5 \%)$ \\
\hline cSLE & $275(9.4 \%)$ \\
\hline SLE & $2383(81.2 \%)$ \\
\hline Age at diagnosis (years) & $31(23-40)$ \\
\hline Disease duration (years) & $9(4-19)$ \\
\hline \multicolumn{2}{|l|}{ Organ involvement* } \\
\hline Skin & $1490(50.7 \%)$ \\
\hline CNS & $561(19.1 \%)$ \\
\hline Joints & $2115(72.0 \%)$ \\
\hline Kidney & $803(27.4 \%)$ \\
\hline Heart & $408(13.9 \%)$ \\
\hline Lungs & $445(15.2 \%)$ \\
\hline \multicolumn{2}{|l|}{ Corticosteroids } \\
\hline Systemic & $1089(37.1 \%)$ \\
\hline Topical & $98(3.3 \%)$ \\
\hline \multicolumn{2}{|l|}{ Immunosuppressants } \\
\hline MMF & $310(10.6 \%)$ \\
\hline AZA & $289(9.8 \%)$ \\
\hline MTX & $240(8.2 \%)$ \\
\hline Other & $123(4.2 \%)$ \\
\hline \multicolumn{2}{|l|}{ Antimalarials } \\
\hline Hydroxychloroquine & $1988(67.7 \%)$ \\
\hline Chloroquine & $47(1.6 \%)$ \\
\hline Mepacrine & $9(0.3 \%)$ \\
\hline \multicolumn{2}{|l|}{ Biologicals } \\
\hline BLM & $84(2.9 \%)$ \\
\hline $\mathrm{RTX}$ & $29(1.0 \%)$ \\
\hline Other & $17(0.6 \%)$ \\
\hline
\end{tabular}

Values were calculated based on available data and are shown as $\mathrm{N}(\%)$ or median (IQR).

${ }^{*}$ Reported by adult and childhood-onset SLE patients (CLE excluded).

AZA, azathioprine; BLM, belimumab; CLE, cutaneous lupus erythematosus; CNS, central nervous system; cSLE, childhoodonset SLE; MMF, mycophenolate mofetil; MTX, methotrexate; RTX, rituximab.

reported not using any antimalarial drug had used HCQ in the past.

\section{Retinopathy screening}

Out of all 1988 patients using HCQ, 1143 (57.5\%) had been diagnosed with lupus in the past 10 years (ie, 20092019). These patients were asked if they had received a baseline retinal screening at the start of HCQ therapy. A

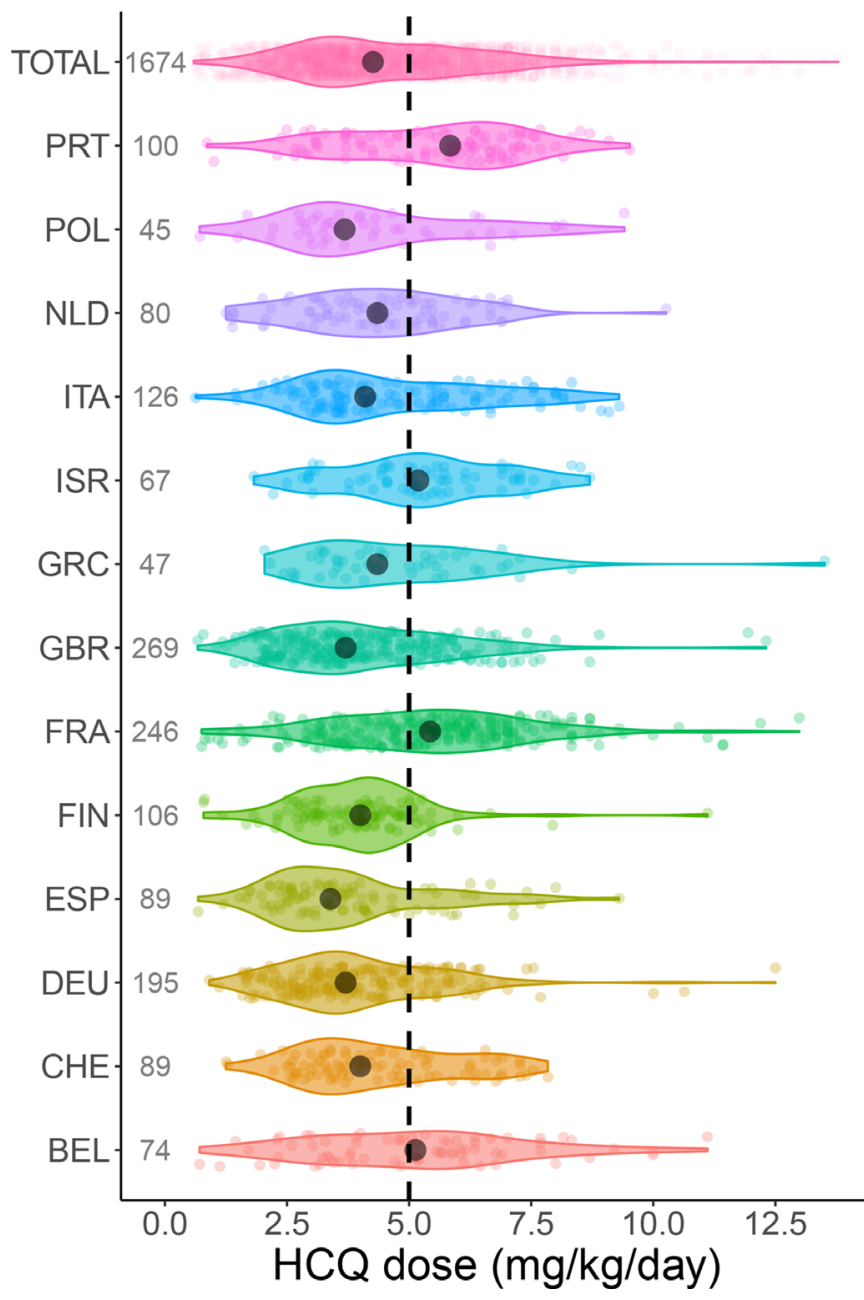

Figure $1 \mathrm{HCQ}$ dose $(\mathrm{mg} / \mathrm{kg} /$ day) reported by patients ( median HCQ dose). Each dot represents a patient, the total number of dots per country is shown in grey. The dashed line represents the maximum recommended HCQ dose of $5 \mathrm{mg} /$ $\mathrm{kg} /$ day actual body weight. BEL, Belgium; CHE, Switzerland; DEU, Germany; ESP, Spain; FIN, Finland; FRA, France; GBR, Great Britain; GRC, Greece; HCQ, hydroxychloroquine; ISR, Israel; ITA, Italy; NLD, Netherlands; POL, Poland; PRT, Portugal.

total of 1017 patients answered this question: $857(84.3 \%)$ replied with 'yes', 160 (15.7\%) with 'no'.

In addition, 1170 out of 1988 patients using HCQ $(58.9 \%)$ reported having used HCQ for $\geq 5$ years. These patients were asked if and how often they receive an eye examination from the ophthalmologist. A total of 1084 patients answered this question, of whom 160 have an eye examination every 3-6 months (14.8\%), 590 every year $(54.4 \%), 174$ every 2 years $(16.1 \%), 105$ every $3-5$ years $(9.7 \%)$ and 55 never $(5.1 \%)$. Overall, only 750 out of 1084 patients $(69.2 \%)$ reported having a regular eye examination at least once a year, as recommended by recent EULAR guidelines. ${ }^{5}$ Retinopathy screening frequencies were compared between 13 countries (figure 2).

\section{HCQ adherence}

Of all 1988 patients using HCQ, 1821 (91.6\%) reported on adherence to HCQ (table 2). In total, 315 patients 


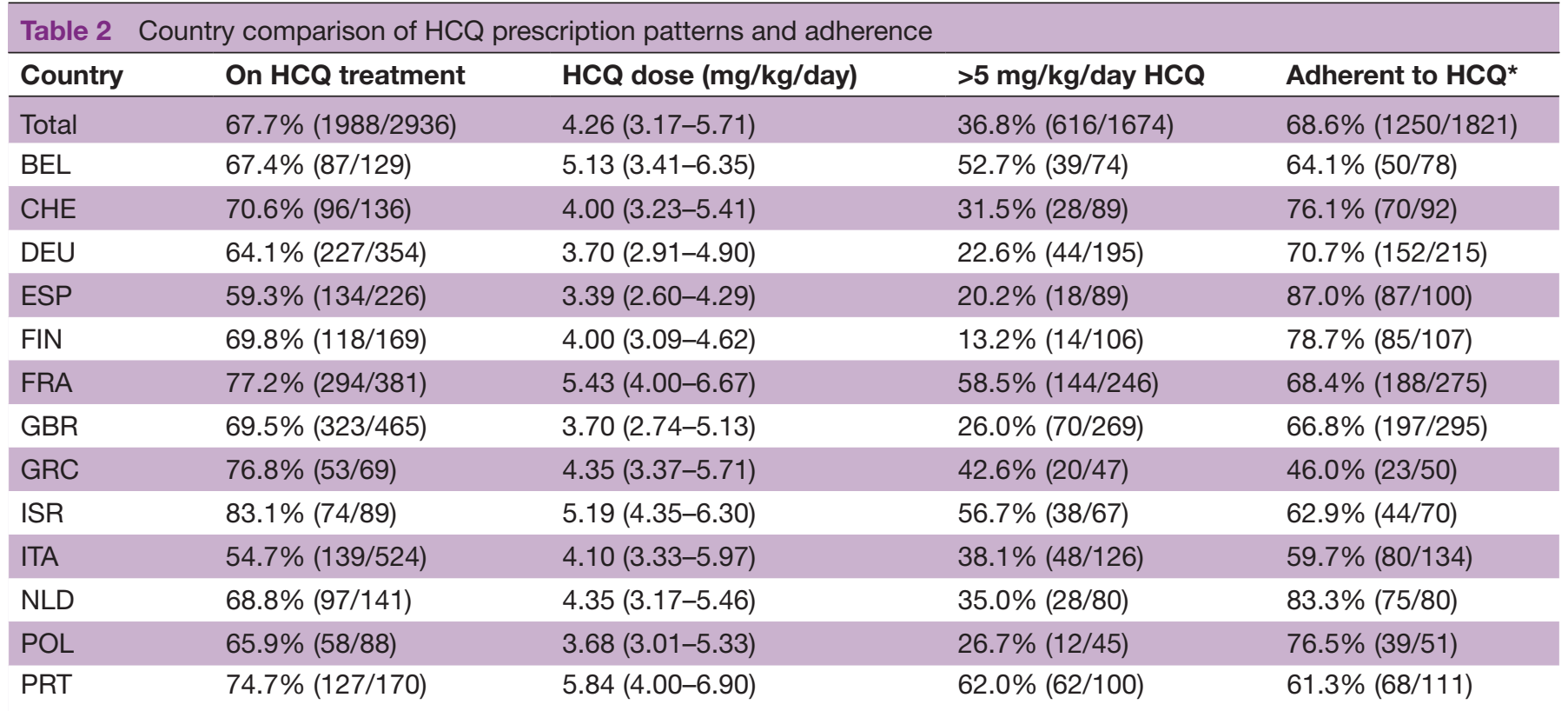

Values were calculated based on available data and are shown as \% (N) or median (IQR).

*This includes patients who have reported to hardly ever skip HCQ.

BEL, Belgium; CHE, Switzerland; DEU, Germany; ESP, Spain; FIN, Finland; FRA, France; GBR, Great Britain; GRC, Greece; HCQ, hydroxychloroquine ; ISR, Israel; ITA, Italy; NLD, Netherlands; POL, Poland; PRT, Portugal.

(17.3\%) reported to skip their prescribed HCQ dose about once a week or more often. An additional 256 patients $(14.1 \%)$ skip HCQ about once a month or once in every 2 weeks. Furthermore, 158 out of 1819 patients $(8.7 \%)$ reported being more likely skipping HCQ than other prescribed medication. On the contrary, 795

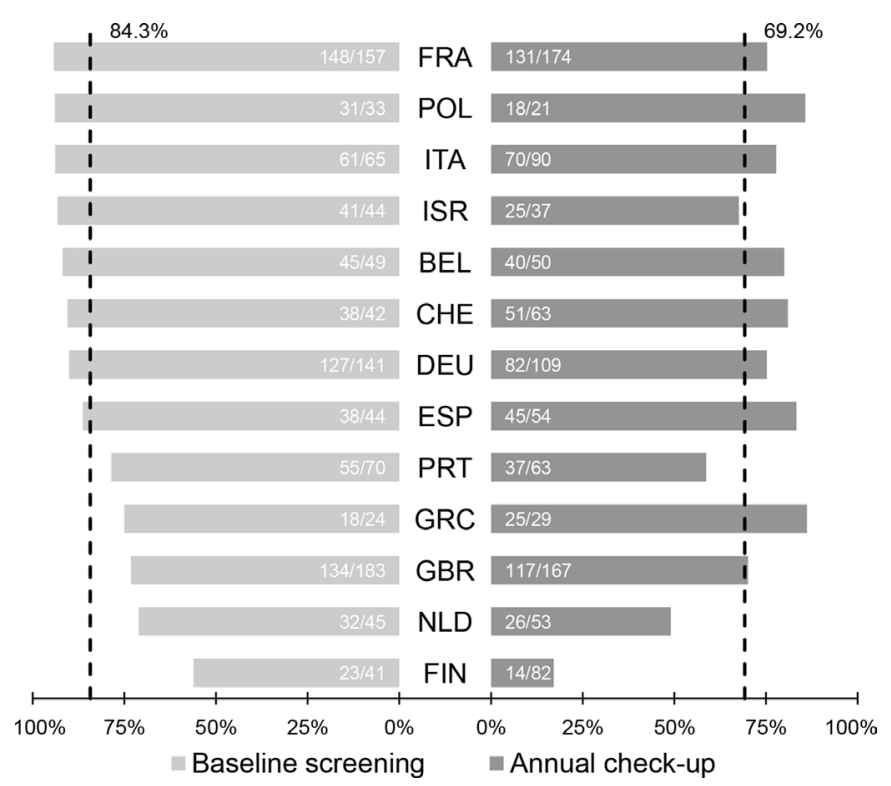

Figure 2 Percentage of patients that reported to have received baseline and annual ophthalmological screening for retinopathy. Absolute numbers are shown in white per country, The dashed line represents the overall screening frequency in Europe. BEL, Belgium; CHE, Switzerland; DEU, Germany; ESP, Spain; FIN, Finland; FRA, France; GBR, Great Britain; GRC, Greece; ITA, Italy; ISR, Israel; NLD, Netherlands; POL, Poland; PRT, Portugal.
(43.6\%) claimed that they are less likely to skip HCQ than other prescribed medication. Moreover, 1250 patients (68.6\%) have reported to hardly ever skip their HCQ. These patients were grouped as being 'adherent' to HCQ. The other 571 patients who reported skipping HCQ more often $(31.4 \%)$ were grouped as being 'non-adherent' to HCQ therapy.

Patients in the adherent group reported use of a significantly higher number of drugs and/or supplements when compared with the non-adherent group (median (IQR): 5 (3-8) vs 4 (2-6), respectively; $\left.\mathrm{W}_{\text {cox }} \mathrm{p}<0.001\right)$. Also, patients in the non-adherent group were significantly younger (median (IQR): 39 years (31-48),

$\left.\mathrm{W}_{\text {cox }} \mathrm{p}<0.001\right)$ and had been diagnosed at a younger age (median (IQR): 28 years $\left.(21-37), \mathrm{W}_{\text {cox }} \mathrm{p}<0.001\right)$ than those in the adherent group (44 years (35-53) and 31 years (23-41), respectively). Of note, there was no significant difference in HCQ adherence between adult SLE and cSLE patients. Furthermore, patients who believed that HCQ was not important or useless for management of their lupus were significantly less likely to adhere to HCQ therapy than those who thought otherwise (hardly ever skip HCQ: $47.9 \%$ vs $70.3 \%$, respectively; $\left.\chi^{2} p<0.001\right)$. Lastly, we found no significant association between HCQ adherence and sex, disease duration, and HCQ treatment duration.

\section{DISCUSSION}

HCQ is commonly prescribed to patients with lupus in Europe. Of note, $67.7 \%$ of patients $(n=1988)$ have reported current use of HCQ and only $7.9 \%$ of patients $(\mathrm{n}=231)$ reported having never been prescribed HCQ. A 
concerning finding is that in $36.8 \%$ of the patients, the recommended maximum daily $\mathrm{HCQ}$ dose of $5 \mathrm{mg} / \mathrm{kg}$ was exceeded. In addition, we found large intra-country and inter-country variations of HCQ dosing in 13 European countries. As high-dose HCQ (ie, $>5 \mathrm{mg} / \mathrm{kg} /$ day) is considered a risk factor for the development of HCQ retinopathy, rheumatologists and other clinicians prescribing HCQ should take into account the patient's actual body weight when prescribing HCQ. Large fluctuations in body weight may require dose adjustment and should be monitored to ensure proper dosing of HCQ within safe margins. To note, in both Europe and the USA, HCQ is often prescribed as $200 \mathrm{mg}$ film-coated tablets, while $100 \mathrm{mg}$ HCQ tablets are available in China ${ }^{12}$ (but not yet approved by the US FDA). Tablets of $100 \mathrm{mg}$ HCQ should also be made available in Europe to enable more accurate dosing of HCQ based on actual body weight.

Regarding retinopathy screening, we have selected patients with lupus diagnosed in the past 10 years to check whether recent guidelines regarding baseline retinopathy screening ${ }^{5}$ was implemented in clinical practice over the past 10 years. We have also selected patients who used HCQ $\geq 5$ years to check if they were receiving annual check-ups as recommended by recent guidelines. ${ }^{5}$ Overall, the majority of patients reported that they received a baseline eye examination during the first year of HCQ treatment (84.3\%). Some countries, however, are performing considerably less well in this respect. In Finland, the Netherlands and Great Britain, less than $75 \%$ of patients reported that they underwent a baseline eye screening. Regarding long-term HCQ use, the results of our study demonstrate that the recent EULAR recommendations ${ }^{5}$ on annual screening for retinopathy are reported far from completely implemented in Europe yet. Patients using $\mathrm{HCQ} \geq 5$ years should be monitored annually to prevent irreversible loss of central vision due to HCQ retinopathy.

Moreover, the results of our study demonstrate that a substantial proportion of patients with lupus (17.3\%) skip HCQ once a week or more often. One of the limitations of the current guidelines regarding dosing of HCQ is that they do not take factors into account that may influence HCQ blood levels in individual patients, for example, individual pharmacodynamics and/or nonadherence. Depending on individual pharmacodynamics and/or non-adherence, actual HCQ blood levels may be higher or lower than expected based on the prescribed dose of HCQ. Non-adherence to HCQ could potentially lower the risk of retinopathy in the individual patient but, importantly, non-adherence has been associated with an increased risk of flares ${ }^{7}$ and should therefore be prevented. Undetectable blood levels of HCQ may be a reliable and objective marker to detect non-adherence, ${ }^{7}$ providing an opportunity to address this issue with patients. Importantly, non-adherence to HCQ was reported more frequently by younger patients, patients diagnosed with lupus at a younger age and patients who were not convinced that HCQ use was important for the management of their disease. These findings urge physicians to communicate the importance of adherence to HCQ therapy by providing clear medication-related information to improve adherence, especially in specific subgroups of patients.

Concerns related to validity and reliability of results are a general limitation of survey studies, and this also holds for the ESLP-19. More importantly, it cannot be expected from patients to recall and/or specify the screening methods used for regular eye examinations. Many of them are unable to do so due to forgetfulness or poor health literacy. We were, therefore, unable to determine whether proper retinopathy screening methods are being implemented in clinical practice, as recommended by recent guidelines. ${ }^{45}$ More research is needed to determine whether proper screening modalities are being employed in Europe.

In conclusion, the results of our study demonstrate that the EULAR recommended guidelines for HCQ dosing and retinopathy screening are incompletely implemented and that non-adherence to HCQ use is frequent in European patients with lupus. Physicians prescribing HCQ should encourage drug adherence and pay more attention to the recent recommendations regarding HCQ dosing and ophthalmologic screening.

Acknowledgements We would like to thank the European Reference Network on Rare and Complex Connective Tissue Diseases (ERN ReCONNET) for reviewing our questionnaire. We also thank Dr Marlies Bloem and Ko Hagoort, MA, for taking the time and effort to review our manuscript. Our special thanks go to all patients who have completed the ESLP-2019. Preliminary results of the ESLP-2019 were presented at the online EULAR 2020 congress.

Contributors ZO, AC, WZ-V and JA have designed, reviewed and coordinated the online questionnaire together with the LUPUS EUROPE Patient Advisory Network and ERN ReCONNET. ZO, TJS and AC have analysed the data and performed statistical analyses. All authors have discussed the results. ZO and TJS wrote the manuscript. All authors and others mentioned in the acknowledgments provided critical feedback and helped shape the manuscript.

Funding The authors have not declared a specific grant for this research from any funding agency in the public, commercial or not-for-profit sectors.

Competing interests $\mathrm{AC}$ and JA report grants from GSK, UCB, Idorsia, Janssen, Boehringer Ingelheim and Leo Pharma during the conduct of the study. RFvV reports grants from BMS, GSK, Lilly, Pfizer, Roche, UCB (outside the submitted work) and is engaged in consultancy (AbbVie, AstraZeneca, Biogen, Biotest, BMS, Galapagos, Gilead, GSK, Janssen, Pfizer, Sanofi, Servier, UCB, Vielabio). IEMB reports personal fees from Sanofi Genzyme, UCB, Amgen and GSK (outside the submitted work).

Patient consent for publication Not required.

Provenance and peer review Not commissioned; externally peer reviewed. Data availability statement Data are available upon reasonable request and will not be publicly available.

Supplemental material This content has been supplied by the author(s). It has not been vetted by BMJ Publishing Group Limited (BMJ) and may not have been peer-reviewed. Any opinions or recommendations discussed are solely those of the author(s) and are not endorsed by BMJ. BMJ disclaims all liability and responsibility arising from any reliance placed on the content. Where the content includes any translated material, BMJ does not warrant the accuracy and reliability of the translations (including but not limited to local regulations, clinical guidelines, terminology, drug names and drug dosages), and is not responsible for any error and/or omissions arising from translation and adaptation or otherwise.

Open access This is an open access article distributed in accordance with the Creative Commons Attribution Non Commercial (CC BY-NC 4.0) license, which permits others to distribute, remix, adapt, build upon this work non-commercially, and license their derivative works on different terms, provided the original work is 
properly cited, appropriate credit is given, any changes made indicated, and the use is non-commercial. See: http://creativecommons.org/licenses/by-nc/4.0/.

\section{ORCID iDs}

Zgjim 0smani http://orcid.org/0000-0001-5210-8943

Thijs J Schrama http://orcid.org/0000-0002-6693-4725

Irene E M Bultink http://orcid.org/0000-0002-5441-3420

Ronald F van Vollenhoven http://orcid.org/0000-0001-6438-8663

\section{REFERENCES}

1 Jorge A, Ung C, Young LH, et al. Hydroxychloroquine retinopathy implications of research advances for rheumatology care. Nat Rev Rheumatol 2018;14:693-703.

2 Wallace DJ, Gudsoorkar VS, Weisman MH, et al. New insights into mechanisms of therapeutic effects of antimalarial agents in SLE. Nat Rev Rheumatol 2012;8:522-33.

3 Marmor MF, Kellner U, Lai TYY, et al. Recommendations on screening for chloroquine and hydroxychloroquine retinopathy (2016 revision). Ophthalmology 2016;123:1386-94.

4 Yusuf IH, Foot B, Galloway J, et al. The Royal College of ophthalmologists recommendations on screening for hydroxychloroquine and chloroquine users in the United Kingdom: Executive summary. Eye 2018;32:1168-73.

5 Fanouriakis A, Kostopoulou M, Alunno A, et al. 2019 update of the EULAR recommendations for the management of systemic lupus erythematosus. Ann Rheum Dis 2019;78:736-45.
6 Osmani Z, Zacouris-Verwij W, Otter SH. Dosing and duration of hydroxychloroquine therapy as a risk factor for retinal toxicity: results of an online survey conducted by the LUPUS/APS Committee of the patient association NVLE. Dutch Journal of Rheumatology 2018;4:40-3.

7 Costedoat-Chalumeau N, Pouchot J, Guettrot-Imbert G, et al. Adherence to treatment in systemic lupus erythematosus patients. Best Pract Res Clin Rheumatol 2013;27:329-40.

8 Malattia C, Martini A. Paediatric-onset systemic lupus erythematosus. Best Pract Res Clin Rheumatol 2013;27:351-62.

9 Bertsias G, loannidis JPA, Boletis J, et al. EULAR recommendations for the management of systemic lupus erythematosus. Report of a task force of the EULAR standing Committee for international clinical studies including therapeutics. Ann Rheum Dis 2008;67:195-205.

10 Bourke BJ, Jones S, Rajammal AK. Hydroxychloroquine and ocular toxicity recommendations on screening. The Royal College of Ophthalmologists in association with The British Society for Rheumatology and the British Association of Dermatologists, 2009.

11 Marmor MF, Kellner U, Lai TYY, et al. Revised recommendations on screening for chloroquine and hydroxychloroquine retinopathy. Ophthalmology 2011;118:415-22.

12 Zhang TY, Zhong B. Meeting the potential emergency global drug supply challenge of hydroxychloroquine for COVID-19. Med Drug Discov 2020;5:100036.

13 Osmani Z, Cornet A, Zacouris-Verweij W, et al. SAT0169 HYDROXYCHLOROQUINE PRESCRIPTION PATTERNS IN EUROPE - THE EUROPEAN SURVEY FOR LUPUS PATIENTS (ESLP). Ann Rheum Dis 2020;79:1025.2-6. 